\title{
Biosynthesis of Zinc Oxide Nanoparticles From Plectranthus Amboinicus and Its Photocatalytic Effect on Wastewater Treatment
}

\author{
Nadana Raja Vadivu Ganapathy, Vasumathi Krishnan, Aruna Janani Veeraraghavan, \\ Varatharajan and Gokul Devaraj
}

\begin{abstract}
Photocatalysis using semiconductor Zinc Oxide $(\mathrm{ZnO})$ is a promising technology for water purification. The current work is aimed at improving the reduction of organic carbon of domestic wastewater by a combination of photocatalysis and Green synthesis. Synthesized zinc oxide nanoparticles from Plectranthus amboinicus was characterized by UV spectroscopy, FTIR, SEM, and XRD. Degradation of organic matter in effluent using Zinc Oxide and Plectranthus amboinicus was examined by the photocatalytic reaction. The reduction of organic carbon was analyzed by $\mathrm{COD}$ and $\mathrm{pH}$ analysis on synthesized $\mathrm{ZnO}$ nanoparticles. The decrease in COD from $800 \mathrm{mg} / \mathrm{l}$ to $50 \mathrm{mg} / \mathrm{l}$ and an increase in $\mathrm{pH}$ from 6.8 to 7.4 results in degradation of organic matter in the effluent. These advantages enable us to reuse the treated water for various purposes such as flushing, gardening, cleaning.
\end{abstract}

Keywords: Zinc Oxide, Plectranthus amboinicus, Photocatalytic reaction, Effluent..

\section{INTRODUCTION}

Various metal oxides performed as a catalyst and applied in the field of environment as it reduces toxicity in water sources. $\mathrm{ZnO}$ has the benchmark application in field of environment and in wastewater treatment. $\mathrm{ZnO}$ has a wide range of applications such as photocatalysis, self-cleaning and environmental purification. Enhancement of $\mathrm{ZnO}$ activity is improved by the advent of nanotechnology, also has a significant impact in photocatalysis [1,2]. Green synthesis of $\mathrm{ZnO}$ nanoparticles from plant-derived materials provide massive importance due to eco-friendly and improve sustainability $[3,4]$. The synthesis of nanomaterials is done by the polyphenols present in the plant materials [5]. Sewage discharged from households, and public places are referred to

Revised Manuscript Received on December 05, 2019

Nadana Raja Vadivu Ganapathy*, Department of Biotechnology, School of Bio and Chemical engineering, Kalasalingam Academy of Research and Education, Krishnakoil-626126,

Vasumathi Krishnan, Department of Biotechnology, School of Bio and Chemical engineering, Kalasalingam Academy of Research and Education, Krishnakoil-626126,

Aruna Janani Veeraraghavan, Department of Chemical Engineering, School of Bio and Chemical engineering, Kalasalingam Academy of Research and Education, Krishnakoil-626126,

Varatharajan Department of Chemical Engineering, School of Bio and Chemical engineering, Kalasalingam Academy of Research and Education, Krishnakoil-626126,

Gokul Devaraj Department of Chemical Engineering, School of Bio and Chemical engineering, Kalasalingam Academy of Research and Education, Krishnakoil-626126, as wastewater. Water pollution, water scarcity, ecosystem, fisheries, agriculture, health issues, etc., are greatly affected due to inadequate infrastructure for wastewater treatment and its maintenance. Green synthesized metal oxide nanoparticles from plant-derived compounds are used for biological treatment.

Plectranthus amboinicus is an aromatic herb native to Cuba and the Pacific Islands used for curing diseases like respiratory issues, cancer prevention, treats fever, etc., [6] Our main objective is to (i) synthesize $\mathrm{ZnO}$ nanoparticles using $P$. amboinicus leaf extract (ii) study the photo-catalytic degradation of sewage water.

\section{II.METHODOLOGY}

\section{A. Extract preparation}

The leaves of $P$. amboinicus were collected from the Department of Biotechnology, KARE. The Collected leaves were cleaned and further surface sterilized with $75 \%$ ethanol The sterilized leaves were washed with distilled water before use. $25 \mathrm{~g}$ of $P$. amboinicus leaves were cut into small pieces and boiled in $30 \mathrm{ml}$ of water for 15 minutes. The extracts were filtered using Whatman No.1 filter paper and refrigerated at $4^{\circ} \mathrm{C}$ until future use.

\section{B. ZnO nanoparticle synthesis}

$0.05 \mathrm{M}$ Zinc acetate and $0.1 \mathrm{M} \mathrm{NaOH}$ were prepared. Later, $10 \mathrm{ml}$ of $\mathrm{NaOH}$ was added dropwise to $10 \mathrm{ml}$ of $0.1 \mathrm{M}$ Zinc acetate hexahydrate aqueous solution and magnetically stirred. The white color precipitated would be appeared. $10 \mathrm{ml}$ leaf extract was added slowly to the solution and kept in Magnetic stirred for four hours. Then, the mixed solution centrifuged at $10000 \mathrm{rpm}$ for 10 minutes to collect the settled particles. The collected particles were subsequently washed with water, and subjected to centrifugation at $1000 \mathrm{rpm}$ for 10 minutes. The centrifuged sample was collected and dried in a hot air oven at $80^{\circ} \mathrm{C}$ for 3 hours, and the dried powder was used for further analysis.

\section{Characterization of $\mathrm{ZnO}$ nanoparticles}

Synthesized nanoparticles were analyzed for the optical property by UV absorption spectra (300-800nm). The functional group's characterization of $\mathrm{ZnO}$ nanoparticles was analyzed using FTIR.

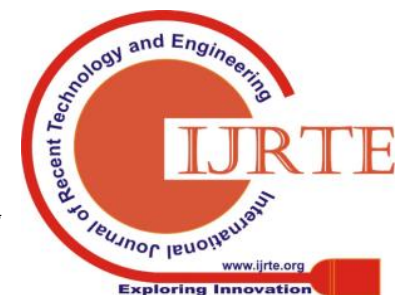


Biosynthesis of Zinc Oxide nanoparticles from Plectranthus amboinicus and its photocatalytic effect on wastewater treatment

The surface morphology was analyzed using SEM. The $\mathrm{x}$-ray diffraction pattern was used for identifying the various form of zinc oxide nanoparticles.

\section{Treatment of wastewater treatment}

The wastewater collected from the Sewage Treatment Plant of Kalasalingam Academy of Research and Education. $50 \mathrm{ml}$ of wastewater sample mixed with $0.005 \mathrm{~g}$ of $\mathrm{ZnO}$ $(0.1 \mathrm{~g} / \mathrm{L})$. And the sample kept in sunlight for 5 hours. The COD value of the wastewater calculated for each one-hour time interval by using a standard titrating procedure. Finally, the $\mathrm{ZnO}$ separated from the wastewater by using primary filtration techniques. $\mathrm{pH}$ meter is used for determining the $\mathrm{pH}$ level in various treatments

\section{RESULTS AND DISCUSSION}

\section{A. UV analysis of $\mathrm{ZnO} \mathrm{NP}$}

UV Spectrum of biosynthesized ZnO NPs showed a strong UV emission at $374 \mathrm{~nm}$; a weak emitting band at $420 \mathrm{~nm}$ (blue emission) was observed (Fig. 1). The UV emission reflects the band edge emission of the wide band gap of $\mathrm{ZnO}$ NPs. The room temperature should be prominent to the purity and crystallinity of the synthesized ZnO NPs. At the same time, the band gap of the material calculated using blue emission as $2.99 \mathrm{eV}$. This shows that the material can go to excited state at the visible light region. So which can able to use as solar photocatalyst. The band gap at $420 \mathrm{~nm}$ is $2.99 \mathrm{ev}$ which is shorter compared to band gap at $374 \mathrm{~nm}$, facilitates the movement of $\mathrm{ZnO} \mathrm{NP}$ to excited state at a visible region which enables us to use biosynthesized $\mathrm{ZnO} \mathrm{NP}$ as solar photocatalyst [7].

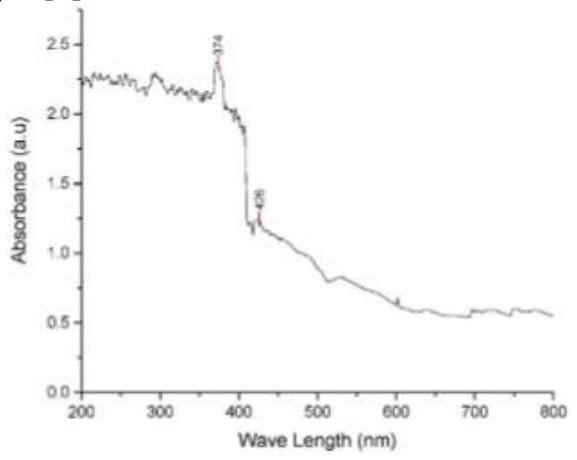

Fig 1: UV Spectrum of ZnO nanoparticles. Two peaks were obtained at $374 \mathrm{~nm}$ and $420 \mathrm{~nm}$.

\section{B. FTIR analysis of $\mathrm{ZnO} \mathrm{NP}$}

FTIR spectra between $500 \mathrm{~cm}^{-1}$ and $4000 \mathrm{~cm}^{-1}$ were examined for $P$. amboinicus leaf extract (Fig. 2). The absorption bands at $3294 \mathrm{~cm}^{-1}$ due to the stretching vibrations of the primary and secondary amines. The intense absorbance at $2194.47 \mathrm{~cm}^{-1}$ and $2150 \mathrm{~cm}^{-1}$ showed the stretching of C-N. The presence of amide band was observed at $1655 \mathrm{~cm}^{-1}$ with the stretching of amide linkages [8,9]. The spectral ranges of FTIR for biosynthesized ZnO NPs were shown in Fig (3). The characteristic bands at $449 \mathrm{~cm}^{-1}$ and $619 \mathrm{~cm}^{-1}$ corresponds to the stretch band of Zinc Oxygen. The peaks at $1024 \mathrm{~cm}^{-1}, 1051 \mathrm{~cm}^{-1}$ were assigned to be symmetric $\mathrm{C}-\mathrm{N}$ vibration associated with a C-O-SO3 [10].

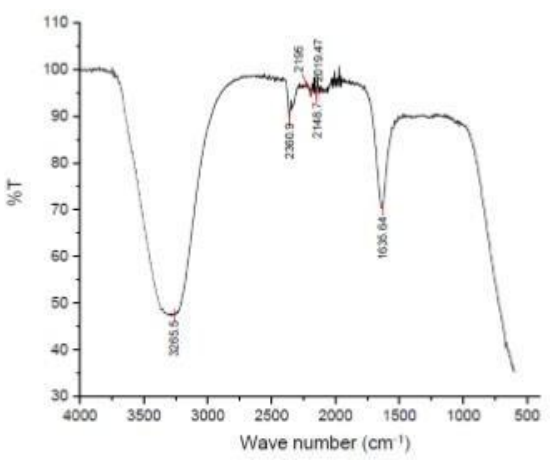

Fig 2: FTIR Spectrum of Plant Leaf Extract. The bands showed the presence of amines, $\mathrm{C}-\mathrm{N}$ and amide linkages.

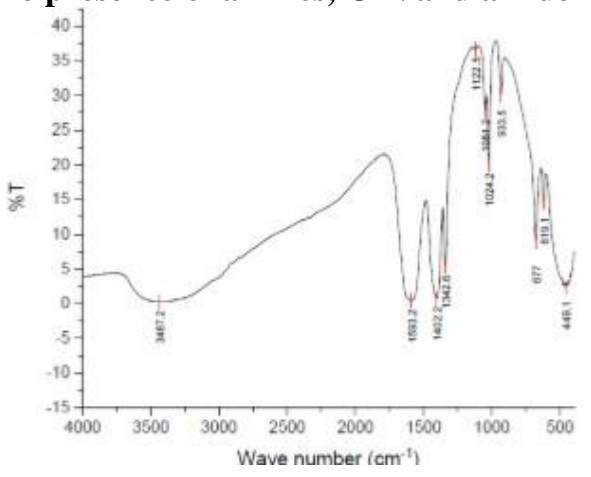

Fig 3: FTIR Spectrum of ZnO NPs.

\section{SEM and XRD analysis}

The SEM image of $\mathrm{ZnO}$ NPs shown in the Fig.4. The morphology of $\mathrm{ZnO}$ nanoparticles appeared to be spherical shaped and is in correlation with the previous studies [11]

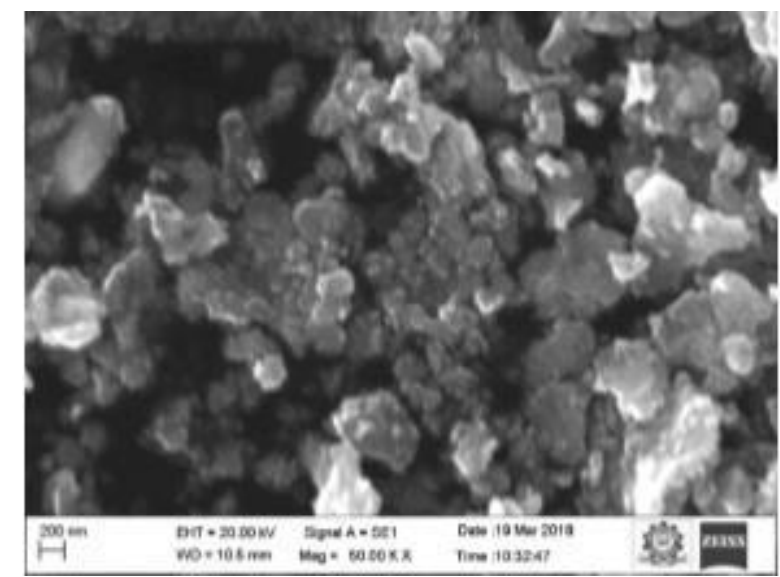

Fig 4: SEM image of ZnO NP

The result of XRD analysis showed that the green synthesized $\mathrm{ZnO}$ NPs were observed to be pure and crystalline in nature. The peaks of XRD analysis revealed various ranges at $31.72^{\circ}, 34.40^{\circ}, 36.22^{\circ}, 47.52^{\circ}, 56.66^{\circ}$, $62.66^{\circ}, 67.98^{\circ}, 69.16^{\circ}$ and it can have indexed to $\left(\begin{array}{lll}1 & 0 & 0\end{array}\right),\left(\begin{array}{ll}0 & 0\end{array}\right.$ 2), (1 $\left.\begin{array}{lll}1 & 0 & 1\end{array}\right),\left(\begin{array}{lll}1 & 0 & 2\end{array}\right),\left(\begin{array}{lll}1 & 1 & 0\end{array}\right),\left(\begin{array}{lll}1 & 0 & 3\end{array}\right),\left(\begin{array}{lll}1 & 1 & 2\end{array}\right)$ and $\left(\begin{array}{lll}2 & 0 & 1\end{array}\right)$ reflection lines of hexagonal wurtzite $\mathrm{ZnO}$ NPs. The average grain size is calculated using

$$
D=K \lambda / \beta \cos \theta \AA
$$

Where $\mathrm{D}$ is an average crystallite size in $\AA$, $K$ is the 
shape factor, $\lambda$ is the wavelength of X-ray $(1.5406 \AA) \mathrm{Cu}-\mathrm{K} \alpha$ radiation, $\theta$ is the Bragg angle, and $\beta$ is the corrected line broadening of the NPs. The average grain size is measured to be $38.1808 \mathrm{~nm}[12]$.

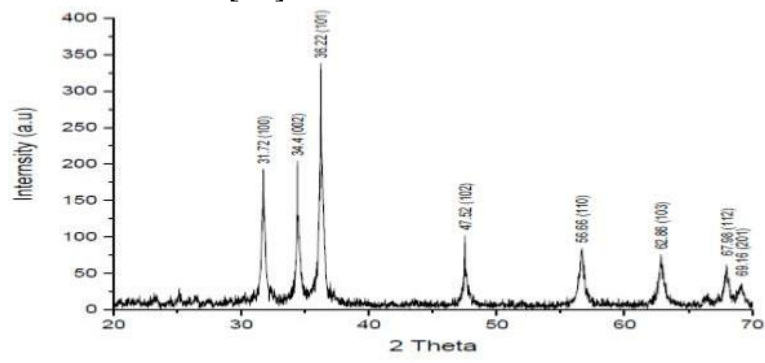

Fig 5: XRD pattern of $\mathrm{ZnO} \mathrm{NP}$

\section{Treatment of Domestic Wastewater}

Domestic wastewater treatment without $\mathrm{ZnO}$ NPs was kept under sunlight for 5 hours. The COD of the sample was found to be constant after the 5 hours of treatment. The COD of the sample was $700 \mathrm{mg} / \mathrm{L}$. The result indicated that solar radiation has no impact on the COD reduction of wastewater within five hours.

Whereas the degradation of wastewater using $\mathrm{ZnO}$ NPs under dark region was performed, COD of the sample slightly decreased from $800 \mathrm{mg} / \mathrm{L}$ to $750 \mathrm{mg} / \mathrm{L}$. The COD of the sample decreased due to adsorption of $\mathrm{ZnO}$ NPs. This shows that the adsorption rate constant is very low.

Treatment of Wastewater using ZnONPs and solar radiation was analyzed for photocatalytic effect. The band gap of the Green synthesized ZnO NPs is $2.99 \mathrm{eV}$. It was capable of reaching an excited state in the visible region. So sunlight used as a light source to treat the wastewater. 0.005 $\mathrm{g}$ of $\mathrm{ZnO}$ NPs added for $50 \mathrm{ml}$ wastewater and kept in sunlight for five hours. COD reduction was calculated for each one-hour time interval. COD of the wastewater decreased up to $93.75 \%$. This shows that $\mathrm{ZnO}$ NPs can reach an excited state and can form free radicals by utilizing photon in solar radiation $[13,14]$

Table 1: COD reduction with respect to time

\begin{tabular}{|l|l|}
\hline Time (hours) & COD (mg/l) \\
\hline 0 & 800 \\
\hline 1 & 500 \\
\hline 2 & 300 \\
\hline 3 & 150 \\
\hline 4 & 100 \\
\hline 5 & 50 \\
\hline
\end{tabular}

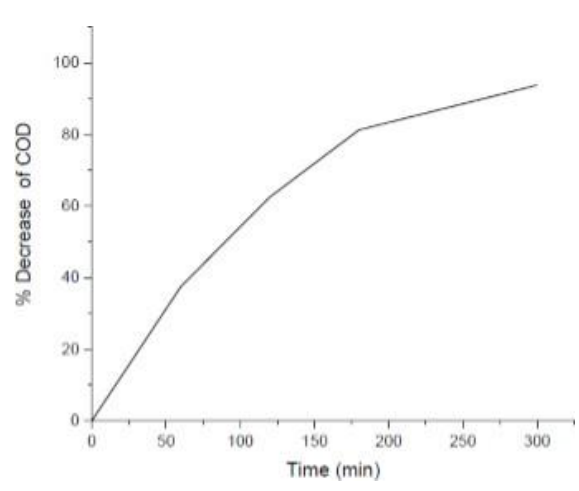

Fig 6. Photocatalytic - ZnO NP treatment shows a drastic reduction of COD.

$\mathrm{pH}$ level remained constant after the 5 hours when Domestic Wastewater treatment without $\mathrm{ZnO}$ NPs. The $\mathrm{pH}$ of the sample retained as 6.82 . This showed that solar radiation has no impact on $\mathrm{pH}$ without $\mathrm{ZnO} \mathrm{Nps}$.

The $\mathrm{pH}$ slightly decreased from 6.80 to 6.85 upon degradation of Wastewater using ZnO NPs under the dark region. The increase of $\mathrm{pH}$ observed in the treatment of wastewater using $\mathrm{ZnO}$ NPs and solar radiation observed for 5 hours, due to the radical formation $[15,16]$.

Table 2 : Effect of $\mathrm{pH}$ with respect to time in wastewater treatment using $\mathrm{ZnO} \mathrm{NP}$ and solar radiation

\begin{tabular}{|l|l|}
\hline Time (h) & $\mathbf{p H}$ \\
\hline 0 & 6.80 \\
\hline 1 & 6.92 \\
\hline 2 & 7.14 \\
\hline 3 & 7.29 \\
\hline 4 & 7.37 \\
\hline 5 & 7.40 \\
\hline
\end{tabular}

\section{CONCLUSION}

The biosynthesized $\mathrm{ZnO}$ nanoparticles using $P$. amboinicus is a low-cost, simple, and effective method to treat wastewater. Biosynthesized $\mathrm{ZnO}$ nanoparticles do not allow bacteria to grow because of its antibacterial activity[7]. The COD of the wastewater decreased to less than $50 \mathrm{mg} / \mathrm{L}$. At the same time the $\mathrm{pH}$ of the wastewater maintained less than 7.5. Our results suggest that the treated wastewater could be used for various purposes and provide an effective outcome for a sustainable environment.

\section{ACKNOWLEDGMENT}

Authors would like to thank Kalasalingam Academy of Research and Education (KARE) management for providing facilities to perform this study in the Department of Biotechnology.

\section{REFERENCES}

1. Kumar, Surabhi Siva, et al. "Synthesis, characterization and optical properties of zinc oxide nanoparticles." International Nano Letters, 3.1, 2013 , pp. 30.

2. Velmurugan, R., and M. Swaminathan. "An efficient nanostructured $\mathrm{ZnO}$ for dye sensitized degradation of Reactive Red 120 dye under solar light." Solar Energy Materials and Solar Cells, 95.3, 2011, pp. 942-950..

3. Elumalai, K., et al. "Bio-approach: plant mediated synthesis of $\mathrm{ZnO}$ nanoparticles and their catalytic reduction of methylene blue and antimicrobial activity." Advanced Powder Technology, 26.6, 2015, pp .1639-1651.

4. Kharissova, Oxana V., et al. "The greener synthesis of nanoparticles." Trends in biotechnology, 31.4, 2013, 240-248..

5. Singh, Henam Premananda, et al. "Biogenic synthesis of metal nanocatalysts using Mimosa pudica leaves for efficient reduction of aromatic nitrocompounds." RSC Advances, 4.71, 2014, pp 37816-37825.

6. Asiimwe, Savina, et al. "Chemical composition and Toxicologica evaluation of the aqueous leaf extracts

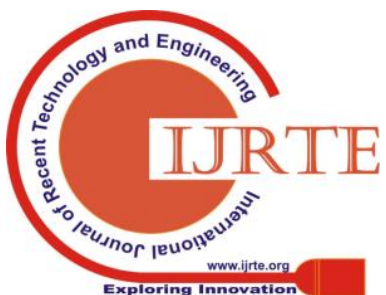


Biosynthesis of Zinc Oxide nanoparticles from Plectranthus amboinicus and its photocatalytic effect on wastewater treatment

of Plectranthus amboinicus (Lour.) Spreng." Int. J. Pharm. Sci. Invent, 3, 2014, pp .19-27.

7. Vijayakumar, S., et al. "Plectranthus amboinicus leaf extract mediated synthesis of zinc oxide nanoparticles and its control of methicillin resistant Staphylococcus aureus biofilm and blood sucking mosquito larvae." Spectrochimica Acta Part A: Molecular and Biomolecular Spectroscopy 137, 2015, pp . 886-891.

8. Basavaraja, S., et al. "Extracellular biosynthesis of silver nanoparticles using the fungus Fusarium semitectum." Materials Research Bulletin, 43.5, 2008, pp . 1164-1170.

9. Philip, Daizy. "Biosynthesis of $\mathrm{Au}, \mathrm{Ag}$ and $\mathrm{Au}-\mathrm{Ag}$ nanoparticles using edible mushroom extract." Spectrochimica Acta Part A: Molecular and Biomolecular Spectroscopy, 73.2, 2009, pp . 374-381..

10. Annamalai, A., et al. "Green synthesis, characterization and antimicrobial activity of Au NPs using Euphorbia hirta L. leaf extract." Colloids and Surfaces B: Biointerfaces, 108, 2013, pp . 60-65..

11. Lingaraju, K., et al. "Biogenic synthesis of zinc oxide nanoparticles using Ruta graveolens (L.) and their antibacterial and antioxidant activities." Applied Nanoscience, 6.5, 2016, pp . 703-710.

12. Fatimah, Is, Rizqi Yulia Pradita, and Annisa Nurfalinda. "Plant extract mediated of $\mathrm{ZnO}$ nanoparticles by using ethanol extract of Mimosa pudica leaves and coffee powder." Procedia engineering, 148, 2016, pp . 43-48.

13. Vaiano, Vincenzo, and Giuseppina Iervolino. "Facile method to immobilize $\mathrm{ZnO}$ particles on glass spheres for the photocatalytic treatment of tannery wastewater." Journal of colloid and interface science, 518 ,2018, pp . 192-199.

14. Gawade, V. V., et al. "Green synthesis of $\mathrm{ZnO}$ nanoparticles by using Calotropis procera leaves for the photodegradation of methyl orange." Journal of Materials Science: Materials in Electronics, 28.18, 2017, pp . 14033-14039

15. Rajamanickam, D., and M. Shanthi. "Photocatalytic degradation of an organic pollutant by zinc oxide-solar process." Arabian Journal of Chemistry, 9, 2016, pp . 1858-S1868

16. Adam, Rania E., et al. "Synthesis of $\mathrm{ZnO}$ nanoparticles by co-precipitation method for solar driven photodegradation of Congo red dye at different pH." Photonics and Nanostructures-Fundamentals and Applications,32,2018, pp . 11-18 